\title{
Globalization and the Changing Face of Educational Leadership: Current Trends and Emerging Dilemmas
}

\author{
David Litz \\ UAE University-UGRU PO BOX 17172 \\ Al Ain, Abu Dhabi, UAE \\ Tel: 971-50-312-7615Ｅ-mail: david.litz@gmail.com
}

Received: March 17, 2011 Accepted: March 30, 2011 doi:10.5539/ies.v4n3p47

\begin{abstract}
This paper has used a deconstructivist conceptual framework in order to explore and analyze the multifaceted and complex impacts of globalization on educational leadership in the early $21^{\text {st }}$ century. It will be argued that globalization has had far-reaching positive and negative effects on all of the various nation-states, cultures, economies, and peoples of the world and that these have also resulted in the emergence and evolution of a variety of interesting and practical educational leadership paradigms and managerial practices. In addition, this paper will conclude with several recommendations that can be used to guide additional research on the varied aspects and trends of educational leadership in a globalized context, and the development of international or cross-cultural international leadership development initiatives.
\end{abstract}

Keywords: Globalization, Education, Educational leadership

\section{Globalization: What Is It?}

There is no question that globalization is an evolving and complicated concept that is difficult to operationalize due to the plethora of definitions and theoretical interpretations that are often used to describe this extremely complex phenomenon. Nevertheless, the most useful descriptions typically imply that globalization is a multifaceted ideological and politically charged process and generally use it as an overarching umbrella term to describe the complex series of economic, social, technological, military and political changes that generally move investment funds, ideas, goods and services, people, and businesses beyond domestic and national boundaries into a larger international realm which, in turn, has the effect of increasing the interdependence and interconnectedness between various people, cultures, ethnic groups, government entities, and organizations from different locations into a wider global arena. As Held, McGrew, Goldblatt, and Perraton (1999) have suggested, globalization is "a process (or set of processes) which embodies a transformation in the spatial organization of social relations and transactions - assessed in terms of their extensity, intensity, velocity and impact—generating transcontinental or interregional flows and networks of activity, interaction, and the exercise of power" (p. 16).

\subsection{A Conceptual Framework for Globalization and Education}

There are many ways in which the concept of globalization has been studied, interpreted and consequently applied to educational contexts during the last 30-40 years. A number of prominent academics have recently analyzed and summarized these approaches and suggest that the concept has been traditionally analyzed through four distinct theoretical waves: (a) theoretical, (b) historical, (c) institutional, and (d) deconstructivist (Held \& McGrew, 2007). These will be discussed in the following section.

As one of the earliest interpretations of its impacts and consequences, the first wave or theoretical approach views globalization as a systematic process of worldwide social change (Held \& McGrew, 2007). Some of the most prominent amongst this group are the 'globalists' or 'hyper-globalists' with their views that the world is entering a truly 'global age' involving the triumph of global capitalism and free markets and the advent of new and distinct trans-national forms of global culture, governance and society (Bruff, 2005; Held \& McGrew, 2007). With respect to education, advocates of this view also believe we are witnessing the demise of the nation state; that post-modernity has undermined the modernist goals of national education and of creating a national culture; and that the increasing importance of information technology and the way that it interacts with global markets will lead to the demise of traditional forms of schooling and educational systems (Held et al., 1999; Tikly, 2001).

Citing little evidence of change as a result of globalization's processes, the historical interpretation questions whether or not there is uniqueness in the current trends of global relations (Held \& McGrew, 2007). Also referred to 
as the 'sceptical approach', this perspective suggests that there has been a growing trend towards 'regionalization' in trade, social movements, and politics yet in this formulation, worldwide capitalism has essentially led to greater polarization between 'developed' and 'developing' countries in addition to a greater significance for nation-states in managing the problems pertaining to capitalism and free-market economies (Bruff, 2006; Held et al., 1999; Held \& McGrew, 2007; Tikly, 2001). Advocates of this view believe that there has not been any meaningful globalization of education and suggest that although various countries' national education systems have become more similar, there is little actual evidence that these systems are disappearing or that nation-states have ceased to control them (Held $e t$ al., 1999; Tikly, 2001). These 'sceptics', therefore, suggest that there has actually been a more modest process of partial internationalization of education involving increased mobility of students and faculty, widespread policy borrowing, and attempts to enhance the international dimension of curricula at secondary and post-secondary levels (Tikly, 2001).

The third stage of the development of the concept of globalization has been referred to as the institutional approach. Essentially, the institutional interpretation explores the impact of globalization as a dialectical process of convergence and divergence in political structures and cultural traditions (Held \& McGrew, 2007). In the sharing of ideas and practices through increased global interactions, countries have the potential to become more homogenized in their policies and cultural habits on the one hand while reactions to dominant cultures produce a heterogenization and strengthening of local or regional cultures on the other. Advocates of this approach are typically referred to as 'transformationalists' and they generally concede that although we are experiencing unprecedented levels of global interconnectedness, globalization should be viewed as a historically contingent process that abounds with contradictions. Thus, although globalization is resulting in greater integration in some areas of the economy, politics, culture, and society, it is also resulting in greater fragmentation and stratification in which some states, societies, regions, communities, ethnic groups etc. are becoming increasingly entwined in the global order while others are becoming increasingly marginalized (Held et al., 1999; Tikly, 2001). With respect to education, globalization is seen by the institutional interpretation or 'transformationalists' as something that is irreversibly modifying the politics of the nation-state as well as its regions, domestic populations, and nationally-defined political, social, economic etc. interest groups and what distinguishes this view is most likely the idea that educational policy is not only affected by globalization, but that it is additionally becoming one of the principle mechanisms by which global forces affect the daily lives of national populations (Tikly, 2001).

The final stage that has evolved in recent years is generally known as the 'deconstructivist' or 'global-revisionist' interpretation and it will form the central backbone of the theoretical framework of this paper. More specifically, this interpretation has arisen out of the 'institutional/transformational' phase and it incorporates post-structuralist and social-constructivist calls for more refined, inclusive, comprehensive and sophisticated descriptions and analyses in addition to a better communication and cross-pollination of ideas on the complex and continuously evolving topic of globalization (Bruff, 2006; Held \& McGrew, 2007). Advocates of this approach recognize that there are many competing and often contradictory interpretations of the processes of globalization which are all intrinsic to the formulation of a broad understanding of the meaning of this phenomenon and they typically call for an increased role of revisionist perspectives that portray this phenomenon as something that is affecting economic, political, cultural and social spheres in a multitude of highly contradictory and uneven ways, but concede that it is certainly not an inevitable, uniform or even linear process. (Held \& McGrew, 2007). These deconstructivists and global revisionists also take into consideration that globalization may be more of a consequence of social change rather than a cause of it and they tend to agree with earlier arguments that the level of recent global interconnectedness is greater now than at any time in history and that it has radically altered power relations and policies at national and international-global levels, yet it is not necessarily a new process. In addition, they recognize the imbalances in the effects of globalization around the world and put a particular emphasis on refuting hegemony and colonialism. Some of the more prominent authors that belong to this particular school of thought include people such as Tikly (2001), Crossley and Tikly (2004) and Shizha (2008), who have convincingly argued that traditional accounts of globalization often ignore the magnitude of the disparities between 'developed' and 'developing' nations and call for post-colonial theoretical frameworks that provide a true voice to the underprivileged, disadvantaged, and low-income countries of the world. Essentially, post-colonialism is a post-modern form of intellectual discourse that specifically addresses the effects of gender, slavery, racism, classism, and ethnicity in colonized societies; the challenges of developing post-colonial national and cultural identities; issues pertaining to migration and diaspora formation; the histories of struggle and resistance against colonial and post-colonial domination and imperialism; questions of languages and language rights; and the ongoing struggles of indigenous people for recognition of their rights (Crossley \& Tikly, 2004; Shizha, 2008). With respect to education, Crossley and Tikly (2004) have pointed out that post-colonialism makes sense to many because the vast majority of educational systems in the world exist in post-colonial societies and have their origins in the colonial era. In addition, 
colonial education has traditionally used European (and increasingly English) languages as the medium for educational discourse (Crossley \& Tikly, 2004) and "many existing education systems still bear the hallmarks of the colonial encounter in that they remain elitist, lack relevance to local realities, and are often at variance with indigenous knowledge systems, values, and beliefs" (Crossley \& Tikly, 2004 p.149).

\section{The Impact of Globalization on Educational Leaders}

Regardless of the way in which one chooses to interpret globalization, its effect can be felt in virtually every aspect of our lives today as "[d]rinking cappuccino and Perrier water, eating sushi, or listening to American or British rock on an iPod while driving the Toyota over to McDonald's dressed in our known-brand jeans are [becoming] increasingly common worldwide activities" (Mulford, 2008 p.10). It is imperative, therefore, that school leaders are able to correctly identify global forces and pressures, adapt to and cope with the large scale changes that will inevitably be thrust upon them, and ultimately recognize that globalization is both a complex and multifaceted process. In addition, educational leaders need to be aware of the fact that globalization can take on many forms and it is becoming increasingly evident that they will need to use several dimensions with which to frame their work in the coming years. Moreover, while some authors such as Tikly (2001) and Burden-Leahy (2009) have rightly suggested that approaches to studying globalization and education must include economic, social and political spheres in order to provide a clearer picture of a particular context, this paper will expand upon this idea and incorporate several more dimensions (i.e. economic, political, American, socio-cultural, demographic, technological, linguistic, and environmental) that have been put forward by theorists such as Berger (2007), Bottery (2006) and Held \& McGrew (2007) in order to provide a more comprehensive description and interpretation of the ways in which globalization is specifically impacting and altering the role of the educational leader in the early $21^{\text {st }}$ century.

\subsection{Economic Globalization}

Humans have been engaged in some form of economic trade or barter system for thousands of years, but the neo-liberal form of economic globalization that has gradually evolved in the $20^{\text {th }}$ century has had enormous positive and negative influences on everyone's lives. There are several reasons why this type of economic globalization has become the predominant form of modern capitalism. The first reason is because of the process of amalgamated 'marketization' (Mortimore, 2001). This refers to the corporate and governmental search for more extensive markets which ultimately results in a shift away from nationally-imposed regulations (e.g. currency exchange controls, interest rates, trade barriers etc.) to a broader international focus on integration and free-market agendas (Mortimore, 2001). A second reason is the collapse of many of the so-called communist or Marxist states in the later part of the $20^{\text {th }}$ century and the subsequent demise of any viable alternative (e.g. socialism, fascism) to global free-market capitalism (Bottery, 2006). A final reason is the rapid and extensive technological advancements in information systems and computer technology (ICT) and the continued expansion of the Internet that have enabled the transfer of information, ideas, and money to virtually any corner of the world (Mortimore, 2001).

There have been many direct effects of neo-liberal economic globalization that educational leaders throughout the world will have to be aware of. First, intensified marketization has led to the creation and locking-in of various countries into free market arrangements with organizations such as the World Bank, International Monetary Fund (IMF) etc. "who stipulate that financial assistance is conditional upon the dismantling of trade barriers and of their entry into a global system of free markets" (Bottery, 2006 p.7). This means that all countries (regardless of their status and wealth) have to essentially play by the same rules so whatever the difficulties or costs of producing particular goods, the price will always have to compete with the lowest available price that is set by the market (Mortimore, 2001). Second, multinational companies are now able to easily transfer their capital, workforces (human capital), factories, and service centers, around the globe in search of worldwide recruitment, cheap labour, and low-priced costs of production. This directly influences government policies, and intensifies competition between governments in their desire to have companies locate business or centers of operations in their respective countries (Bottery, 2006). Third, as just noted, international funds can easily travel around the world in search of larger profits. This has the effect of giving specialized brokerage firms, individual traders, as well as currency dealers a great deal of influence and control over currency valuations, exchange rates, and stock markets (Mortimore, 2001). Fourth, companies can increasingly conduct a great deal of their business in cyberspace and thereby avoid paying national taxes. This results in a reduction of the funds that national governments have available to invest in public services and infrastructure (Mortimore, 2001). Lastly, economic globalization has led to the inevitable expansion of private-sector interests into public and cultural domains. This has created a situation in which private-sector business values such as efficiency, productivity, effectiveness (Bottery, 2006), constant change or reform, and organizational learning have become commonplace in many aspects of society (including education). In addition, cultural goods (e.g. art and music) have been turned into "articles or activities for consumption. They may also be [increasingly] standardized, with a resulting extraction of local individuality" (Bottery, 2006 p.7). 
Although the effects of economic globalization have led to drastic changes in societies such as shifts in the traditional roles and power of the nation-state and the increase of influence of multi-national corporations throughout the world, its impact on developing countries has been even more profound. This is due to the fact that developed nations "have skewed the game of global trading to favour themselves: whist preaching the mantra of free-market competition, most historically did not achieve their premier status in this way, and most continue to subsidize their own producers to prevent emergent countries from selling their products [in]...developed [countries]" (Bottery, 2006 p.8). As a result, the poor continue to get poorer in many parts of the developing world while the rich continue to get richer. There are of course some notable exceptions to this such as the expanding economies of India, Brazil, China, and the oil-rich sheikhdoms of the Gulf, but the situation in these countries is still very much unique.

Poverty and other economic inequalities have had some major impacts on developing countries as they have often led to a lack of adequate funding and the insufficient provision of resources for education systems in these nations (Bush \& Oduro, 2006; Guttman, 2003). According to Robertson, Novelli, Dale, Tikly, Dachi, and Alphonce (2007), this has not only resulted in the need for substantive educational development policies and the necessary provision of aid, but is has additionally resulted in international, local, and regional dynamics of translating policies into practice in which multilateral agencies such as the World Bank, UNESCO, IMF etc. and national governments continue to vie for different roles. Moreover, Robertson et al. (2007) have suggested that the developing world has gradually seen a shift away from altruistic aid programs directed at national planning assistance to neo-liberal market approaches (i.e. the Washington 'consensus') designed to introduce structural adjustment programs, tap into markets, and expand economies whereas in recent years the effects of the September $11^{\text {th }}$ attacks on the USA have had the effect of changing overseas aid flows to being only partially concerned with poverty and inequality reduction and more to do with changing attitudes towards the West. While these types of conventional 'development' initiatives have undoubtedly exacerbated colonial disparities and resulted in a number of other unfortunate inequalities and subversive elements and agendas, they have also had the positive effect of intensifying recent calls for an increased role of grassroots or home-grown economic, political, and social programmes and movements in a number of countries. While still in their infancy, these changes are giving an increased voice to the masses of the so-called developing world as well as changing the ways in which traditional forms of educational development are perceived.

\subsection{Political Globalization}

Historians often link the rise of the modern nation-state (in Europe and North America in the $19^{\text {th }}$ century and in Asia, Latin America, and Africa in the $20^{\text {th }}$ century) with the process of industrialization and the development of modern (i.e. neo-liberal economics) capitalist and socialist economies (Frank, 2002; Kennedy, 1987; Social Science Research Council, n.d.). These theorists also assert that the administrative structures and institutions of the modern nation-state were partly responsible for the conditions that led to intensive industrial expansion (Frank, 2002; Kennedy, 1987; Social Science Research Council, n.d.) and that industrial development brought with it massive population dislocations and other forms of social disarray that ultimately necessitated state intervention in the form of public education and social services (e.g. health care, housing, pensions etc.). Consequently, the development of the modern nation-state, nationalism, inter-state alliances, colonization, and the great wars of the $19^{\text {th }}$ and $20^{\text {th }}$ centuries were the result of fairly significant political changes in the global structure of economic production (Frank, 2002; Kennedy, 1987; Social Science Research Council, n.d.).

Another aspect of modern political globalization that was typical of most of the $20^{\text {th }}$ century was the ideological struggle between the Western nations, (i.e. the United States and its allies, and the Eastern Bloc, the Soviet Union and China and their allies) and the gradual de-colonization of Asia, Latin America, and Africa into a plethora of new nation-states (Kennedy, 1987; Social Science Research Council, n.d.). While many of the new nation-states of Africa, Latin America, and Asia had based their struggle for independence on basic anti-colonial principles of freedom, justice, and liberty, the economic, political, and ideological competition between the 'Eastern' and 'Western' blocs found a crucial foothold in these newly independent nation-states as well. As a result, the Cold War never developed into a situation involving actual military conflict in Europe or North America, but instead produced a vast array of civil wars within and wars between new nation-states in the developing world which were fuelled and supported by Cold War tensions (Kennedy, 1987; Social Science Research Council, n.d.). Over the longer term, these conflicts have had the unfortunate effect of exacerbating the disparity of wealth between the developed and developing world in addition to playing a major part in contributing to an incessant cycle of violence and conflict; the continuation of corrupt and despotic governments and 'puppet' regimes; intensified environmental degradation; ongoing internal and external displacement and migration; shifting allegiances; a backlash against imperial powers and a rise in radical post-colonial nationalism; and the emergence of religious (i.e. Islamic) fundamentalism. 
A third aspect of political globalization that has characterized the $20^{\text {th }}$ and early $21^{\text {st }}$ centuries has been the demise of the Soviet Union and the Eastern bloc and the subsequent acceleration of increased openness throughout many parts of the world. Instead of the politics of containment, many countries have come to gradually support policies in favour of free trade (Frank, 2002; Mortimore, 2001; Social Science Research Council, n.d.) and 'Western' principles of democracy and fundamental rights and freedoms. With such a focus on increased worldwide openness, we have seen a partial relinquishing of power by individual nations to larger international entities such as the European Economic Union (EU), North American Free Trade Agreement (NAFTA), Association of South East Asian Nations (ASEAN), Asia Pacific Economic Cooperation (APEC) etc. We have also seen "multilateral organizations, and in particular the United Nations (UN), [gradually change]...their focus from maintaining the balance of power between the East and West to a more global approach to peacekeeping/peace-building, development, environmental protection, protection of human rights, and the maintenance of the rule of law internationally" (Social Science Research Council, n.d.). In addition, this new brand of political globalization has been paradoxically manifested through the "relocation of [people's] commitment and identity to levels below that of current nation states-and educators need to be aware of such diverse commitments, and the demands and tensions that will spring from them" (Bottery, 2006 p.9). Such commitments could occur on a regional or local level and they can be exemplified by identifications with particular ethnic, social, and cultural groups as well.

A final element of political globalization that cannot be ignored are recent arguments that extol the 'end of history' thesis and suggest that in terms of the great political systems debate among communism, fascism, and democracy, democracy and a modern neo-liberal mixed economy seem to have won in North America, Europe, and a handful of other countries, but in many parts of the developing world the debate still rages on (Wiarda, 2007). There, not only are a variety of outcomes still possible, including civil war, state failure, and societal collapse, but most developing or so-called third world nations exhibit mixed, emerging, traditional and even hybrid forms of government (e.g. post-colonial, neo-Marxist, Sheikhdoms etc.) that could very well continue far into the future as well (Wiarda, 2007). This has enormous implications for 'Western' foreign-policy initiatives such as the often too-hasty and precipitous efforts to establish pristine democracies in countries that are ill-prepared or ill-equipped for them socially, culturally, economically, and politically (Wiarda, 2007). In addition, it may also have enormous repercussions with respect to international relations and the exacerbation of ongoing tensions between the developed and developing worlds.

Bottery (2006) has suggested that there are a number of ways in which the aspects of political globalization will directly affect educators in the coming years. First, global political and social agendas may continue to be influenced by biased economic agendas on a number of different local/regional, national, and international levels and this is likely to lead to problems in the development of common curricula. Second, the emergence of commitments and identities to entities and groups other than the nation-state may ultimately result in situations in which educators are forced to promote national or even international versions of citizenship, whilst their true loyalties and allegiances may be increasingly located elsewhere. Finally, "the mediation of...global forces at [international, regional/local,] national or cultural [and social] levels is likely to make the political future extremely difficult to comprehend, predict or control. [As a result,] educators may then not only experience greater control and direction of their work, but an increasing complexity and fragmentation around them as well" (Bottery, 2006 p.9).

\subsection{American Globalization}

Some theorists such as Beare (2007) have predicted that the world's population centre is moving inexorably to regions such as China, India, and Central Africa so the $21^{\text {st }}$ century will inevitably see the development of a non-European and non-'Western' cultural orientation that is dominated by black, Asian, and pre-dominantly non-Christian countries and cultures. While some aspects of Beare's (2007) argument make sense and there is no question that the future might see a more multi-cultural, multi-faith, and multi-lingual world, authors such as Freedman (2009) and Rego (2007) have recently suggested that it is far more probable that the USA will continue to hold on to its pre-eminent military, economic, and socio-cultural position in a broader international arena for the foreseeable future because of several features which distinguish it from the dominant great empires of the past. The first is the fact that American power is based on alliances and cultural influence, rather than colonies while the second is the USA's deep association with an ideology that is based on the rule of law, flexible, potentially universal, and inherently subversive of alternative ideologies.

Both Freedman (2009) and Rego (2007) have pointed out that people have been looking for a so-called peer competitor to emerge and gradually displace the USA for many years, but this has never occurred. One reason for this is the fact that state socialism and other similar alternatives have been largely discredited as an alternative to the American neo-liberal capitalist (laissez-faire) ethos and no other viable or effective option has been made available to this point. China, for instance, has embraced the neo-capitalist model, but all too often finds itself being forced to confront too many crises of its own such as deep social inequalities; widespread environmental damage; 
demographic pressures; and political dysfunctions so it still cannot seriously challenge the USA (Freedman, 2009). Russia, on the other hand, has significant ambitions yet it is finding that it is increasingly difficult to have a major economic or cultural impact beyond its own regional or peripheral sphere of influence (Freedman, 2009). In addition, the Islamic world will undoubtedly create regional crises and pose security threats. However, it is also unlikely that it will threaten the economic and military supremacy of the USA as a competing superpower model because extreme fundamentalist Islamists are generally only a minority of a minority and they have no economic program of which to speak (Freedman, 2009). Finally, the European countries that have the desire to compete with the USA do not have the actual capabilities while those that have the potential to develop the capabilities do not have the genuine desire (Freedman, 2009; Rego, 2007).

Despite America's growing dependency on oil and increasing military engagements, Freedman (2009) and Rego (2007) have suggested that another reason for America's continued prominence, competitiveness, and advantage in the world is its economic flexibility that none of the more authoritarian alternatives posses. This is particularly true in times of crisis such as the recent global economic recession. Rego (2007), for example, has argued that America is a multicultural and multiethnic (heterogeneous) country with an extremely diversified and adaptable labour market that is located in a competitive geographic position. Moreover, even though the American economy is based on the principles of free enterprise, it is not entirely laissez-faire in the sense that a great deal of transparent and fair regulation of the marketplace exists to ensure a rather level-playing field, with relatively little corruption and plenty of safe-guards for those who make investments or enter into contracts (Rego, 2007). Freedman (2009), on the other hand, has pointed out that neo-liberal democracies such as the USA make for flexibility by allowing discontent to be expressed, channelled, and absorbed while the free-market economies that often characterize neo-liberal democracies also make for flexibility by allowing for survival through times of economic hardship (e.g. recessions, depressions etc.) without considerable long-term damage to a country's position in the world. As a result, if the USA stays close to its allies and true to its core values, it's "elasticity should give it a resilience, flexibility and capacity to adjust to adversity that has been lacking among the great powers of the past" (Freedman, 2009).

Whether one agrees with the ongoing and continued supremacy of America or not, there can be no denying that its influence and values will ultimately penetrate the workings and functioning of every nation-state in the world so its impact on education cannot be overlooked. Some of these effects might include an expansion of American notions of educational change and reform; models of funding mechanisms, curricula, pedagogy, assessments, and organizational structures; and paradigms or conceptual frameworks on which to base educational research as well as leader development and teacher in-service programs (Bottery, 2006). In addition, US military intervention is becomingly increasingly difficult to predict while the influence of its soft power (i.e. food, fashion, film, and political values) will continue to exert a growing amount of pressure upon other cultures and countries (Rego, 2007). As such, educational leaders will need to not only be able to fully comprehend these widespread effects, but they will also need to be to effectively respond to their impact upon local, national, and international identities and cultures as well as specific educational communities (Bottery, 2006).

\subsection{Socio-cultural Globalization}

Bottery (2006) has argued that the influence of socio-cultural globalization can be seen in two different ways and that it is absolutely essential for educational leaders to be aware of their causes, characteristics, synergies, annoyances, dangers, and possibilities. The first type is known as 'globalization of a cultural variety' and it generally refers to the way in which people are now able to eat any type of food, attend any religious ceremony, watch or listen to any kind of news report, music or sporting event etc. in virtually any location throughout the world. This has the obvious effect of allowing people to gain useful insights and differing perspectives on a variety of issues, lifestyles, worldviews etc., but it can also have the effect of only giving some people a superficial understanding of dissimilar thoughts, ideas, meanings, and values. In addition, some people may respond to these aforementioned cultural varieties of globalization as if they were negative or manipulative influences to their deep-held beliefs and this may cause these people to react with indifference as well as rigidity and outright physical resistance (Bottery, 2006).

Bottery (2006) has referred to the second type of socio-cultural globalization as a 'globalization of cultural standardization' in the sense that it "operates through the imposition of a one-window view of the world" (p.11). In this contextualization, predominant cultural (i.e. American) aspects are extracted, reconfigured, packaged, and marketed for consumption by other cultures and people as a profit-making activity (Bottery, 2006; Klein, 2000; Smith, 2002). While there are obvious positive economic effects associated with this type of cultural uniformity, Bottery (2006), has pointed out that "[w] hen education systems are influenced by such activities, instead of liberating potential they may instead constrain experience and shackle the spiritual" (p.11). It is absolutely essential; therefore, that the educational leader is not only aware of the complex processes and mechanisms involved in 
cultural standardization, but that they are also able to understand the serious ramifications of this form of globalization on educational systems and the broader context in which they operate.

\subsection{Demographic Globalization}

Bottery (2006) has pointed out that the people in most 'Western' nations are living much longer and that this will likely result in a need for more governmental social assistance for elderly people in addition to placing a larger drain on governmental pension and investment schemes. At the same time; however, more and more people are having fewer and fewer children nowadays so this will ultimately have the effect of decreasing the numbers of people working and paying taxes that are required to finance public welfare institutions that support elderly people (e.g. government-provided health care, social insurance etc.) as well as other vital social services. Moreover, this potential lack of funding for public sectors could be exacerbated further as an increasing aging population that wields greater political power and influence, might also possibly attempt to bias public spending to suit its own needs, rather than invest in things such as education (Bottery, 2006). Such a situation would be both complex and very difficult for school leaders to navigate.

There are a number of possible solutions for dealing with the demographic crisis facing most 'Western' nations. The first possibility is the maintenance of population levels through immigration. While this would assist some people in developing nations to improve their quality of life and provide a larger pool of workers in 'Western' nations, it is difficult to sustain and produces its own complex socio-political and cultural problems (Bottery, 2006). Other solutions have included attempts at increasing workers' productivity; encouraging less reliance on state pensions in favour of private schemes; reducing state benefits; and increasing the age at which people can retire, but most of these have only had the end result of merely provoking negative reactions, poor morale, and societal resentment (Bottery, 2006). Moreover, when coupled with the additional problems associated with an increasingly over-burdened younger generation, this type of social discontent is something that could have potentially serious and toxic consequences on educational systems so school leaders will need to be vigilant of this in the future.

While some of the more advanced developing nations such as Brazil, Argentina, Malaysia, Thailand, and India still have healthy birth rates and will be able to continue having growing pools of labour for the foreseeable future, it is expected that they too will eventually experience demographic decline and similar budgetary and socio-political concerns as many 'Western' countries (Bottery, 2006). On the other hand, the situation in the poorest developing countries is a little different and it is to be expected that these countries will continue to be dependent on central economies such as the USA where capital and technical expertise tend to be located. In addition, birth and death rates will continue to be high and the quality of people's lives will continue to be substandard unless genuine, effective, and sustained poverty reduction and educational development programs are undertaken in the future (Guttman, 2003; Robertson et al., 2007). This may prove to be difficult, however, as the wealthier countries in the world are not only likely to be faced with reoccurring turbulent economic cycles and depleting natural resources, but they may also find themselves increasingly burdened with assisting their own aging populations so there is the distinct possibility that fewer funds and other forms of assistance will be made available in the coming years.

\subsection{Environmental Globalization}

The massive and widespread pressures on the global environment have been well documented and Bottery (2006) has referred to this form of globalization as an "expression of a concern with the ecology and global interdependence of living things, and particularly with humanity's influence upon such processes" (p.14). Although it is well beyond the scope of this paper, some specific environmental issues in the world include, but are not limited to; global warming; pollution; resource depletion; rising populations; desertification; habitat destruction etc. and these types of problems often transcend national borders and impact many people. As such, the global environment is no longer just the concern of scientists, policy-makers and politicians, but it is also the concern of schools and educational leaders as well. Some of the ways in which environmental concerns might be dealt with by educationalists in the coming years could include analyses of how we can learn to be more responsible and sustainable citizens of the globe; how we should define the roles of individuals in a community and their impact on, and stewardship of, the environment; and the development of an understanding of how we can best encourage, create, and maintain sustainable forms of educational leadership (Mulford, 2008).

\subsection{Linguistic Globalization}

In a sociolinguistic context, a global language refers almost literally to its use as a common language for the world and a language only achieves this status because of the special role and significance that is attached to it by virtually every country of the world (Crystal, 2003; Phillipson, 1992). While the world has seen different languages (e.g. Latin, Greek etc.) take this status during different historical eras, we have witnessed the gradual penetration and dominance of English as a global language of politics, business, communication, information technology, media, 
and entertainment (Bottery, 2006; Crystal, 2003) in the $20^{\text {th }}$ and early $21^{\text {st }}$ centuries. In addition, English is spoken on every continent and it used officially in 70 countries and without government sanction in at least 20 more. Moreover, over 400 million people speak English as their mother tongue while 50 million study it at the primary level as an additional language and another 80 million study it at the secondary level (Crystal, 2003).

Although the current form of global English originated in the spread of the British Empire, its continuation and pre-eminence is seen as liberating and functional on the one hand, and being connected to the spread of 'Western' neo-liberal capitalism and American cultural globalization on the other. Consequently, its use has created a love-hate relationship for many people throughout the world (Bottery, 2006). Some that are in favour of English as a global language might suggest that is not only the voice of America, but that it is also becoming the language of the young in the developing world, the formerly powerful world, and the world that is yearning for democracy. It is has also been argued that English is becoming a global language unlike any other in history in the sense that it its widespread usage and many variations enable it to be considered as a classless language that encompasses more than just a convenient means of communication among the world's global citizens. In this way it can be seen as an ideological movement, even if by accident (Crystal, 2003).

Some theorists, on the other hand, have the opinion that English isn't suitable for use as an international language. The first reason that is typically used is that English is predominantly a national language and no national language should be suitable for international use. Moreover, if we accept a national language as international, it will give enormous political and cultural advantages to the country or countries for which the chosen language is the native tongue while serving to diminish the value, prestige and usefulness of many of the world's other languages (Crystal, 2003; Guo \& Beckett, 2008; Phillipson, 1992). Second, English is considered very difficult for some people and cultures to learn and if we automatically make English an accepted international language, $90 \%$ of people of the world who don't know English will be unreasonably or unfairly discriminated against (Crystal, 2003). A final reason that people have put forward against the use of English as an international language concerns its function as an agent of imperialism or American hegemony. To these critics, English is rapidly sweeping the planet's physical, economic, cultural, and cyber space at an alarming rate and brand names such as Hollywood, Coca-Cola, Microsoft, The Gap etc. are not only linked to American products, but they are also increasingly becoming associated with a global consumerist culture that is spread through a common language (Crystal, 2003).

Whether one agrees or disagrees with the use of English as a global language, its continued use throughout the globe is not in doubt. As a result, educational leaders in both developed and developing contexts will not only find themselves involved in the debates surrounding its proper usage, but they will also need to help prepare their respective school systems, curricula etc. for the growing demand for English as a second/foreign language instruction from both native and non-native English speaking teachers. At the same time, however, they will undoubtedly face considerable pressure to help ensure that the remaining world's languages are not lost and that people who are non-native speakers of English as well as those who do not speak English at all are not discriminated against (Guo \& Beckett, 2008).

\subsection{Technological Globalization}

The past two decades have seen an unsurpassed internationalization of information services involving the exponential expansion of computer-based communication through the Internet, email, mobile phones, and computer systems. On the one hand, this electronic revolution has promoted economic expansion and the diversification and democratization of information as people and organizations in nearly every country are able to conduct business online and transfer money to any location in addition to communicating their opinions and perspectives on the various local and global issues that impact their lives (Guttman, 2003). On the other hand, this expansion of information has often been highly uneven, resulting in a 'digital divide' (i.e. differences in the access to and skills to use the Internet and other information technologies) between the developed and developing world as access to things such as information technology, telephone lines, mobile phone networks etc. in many developing countries are often controlled by the state or only available to a small minority that not only understand how to use these devices, but are also able to afford them (Guttman, 2003; Social Science Research Council, n.d).

A second major impact of technological globalization is the fact that no field of human endeavor (i.e. manufacturing, financial services, politics, science, education, health, culture etc.) will be left untouched because "the market place is global and highly competitive, forcing individuals, firms, and entire nations to adapt and improve their skills continually in order to compete effectively...[T]he competitive edge [,therefore,] belongs to those with the capacity to create new knowledge and apply it rapidly...to a wide range of human activities" (Guttman, 2003 p.16). While this type of scenario will undoubtedly lead to calls for governments to take a greater interest in forming highly skilled workforces, the private sector will inevitably call for more efficient work organizations and for their 
employees to have better computing, communication, problem solving, and entrepreneurial skills, and the flexibility and continuous upgrading required to keep pace with the speed of change in the future (Guttman, 2003). Unfortunately, the fast changing patterns of trade and commerce, coupled with technical innovations, make it very difficult to predict what specific skills will be needed in the years ahead (Guttman, 2003). It also creates a situation whereby wealthier countries, corporations, and segments of society are, by their very nature, in a better position to adapt, transform, and acquire the necessary knowledge or skill-sets that will be required to continuously excel in this new context of constant change and transformation while those with limited resources will ultimately fall further behind.

A third way in which information technology has had a major impact on the world can be seen in the arena of popular culture. Essentially, information technology and modern communications have enabled a diverse array of locally-based popular culture to develop and reach a wider audience. World music, for instance, has evolved into a major musical tradition and has developed a major audience (Social Science Research Council, n.d.). On the other hand, globalization has increased the transmission of popular culture from the developed world throughout the rest of the world. As a result, despite nationally-based efforts to establish local movies, television programs etc. many media markets in Latin America, Africa, and Asia continue to be saturated with productions from the USA, Europe, and a few countries in Asia (e.g. Japan and India) (Smith, 2002; Smith \& Smith, 2002; Social Science Research Council, n.d). Critics of this trend have not only pointed out the unfortunate contribution that this has made to the silencing of domestic cultural expression, but they have also warned against the dangers of the hegemonic reach of dominating and alien cultures and the potential homogenization of values and cultural tastes throughout the world (Klein, 2000; Smith, 2002; Smith \& Smith, 2002; Social Science Research Council, n.d.).

Another way in which information technology has had a major impact on globalization is the way in which it has revolutionized and shifted the transmission and reporting of world news with the rise of global news services (Social Science Research Council, n.d). "This process has been referred to as the 'CNN-ization of news', reflecting the power of a few news agencies to construct and disseminate news" (Social Science Research Council, n.d) via satellite technology to virtually and corner of the globe. While this is certainly beneficial to many, it also raises a number of questions such as: Who determines what news is actually newsworthy? Who structures and frames the news and determines the viewpoints that are articulated? Whose voices are and are not represented through the various global news competitors (e.g. CNN, FOX, BBC, CBC, Al-Jazeera)? Finally, what are the potential consequences of silencing alternative voices and perspectives (Social Science Research Council, n.d)?

Despite several counter-arguments (i.e. lack of hard, replicable evidence of educational impact, unfulfilled expectations of revolutionary changes, need for long-term investment and high recurrent costs), the intense pressure for a more rapid infusion of ICT into education will be a final way in which technological globalization will have an enormous effect on the work of educational leaders, schools, and school systems (particularly in developed nations) (Hepp, Hinostroza, Laval, \& Rehbein, 2004). There are several obvious reasons for this. First, because ICTs pervade every aspect of work and life and are the preeminent tools for information processing, new generations will need to acquire the necessary skills to become competent in their use. In addition, schools are information and knowledge handling institutions so it makes sense that ICT will inevitably become the fundamental management tool for entire educational systems. Finally, schools routinely and profoundly revise existing teaching practices and resources or tools in order to create more effective learning environments and improve life-long learning skills in their students. ICTs are versatile and powerful tools that can greatly assist in this purpose so they will likely be present in as many classrooms or schools that can afford and acquire them (Hepp et al., 2004).

In terms of educational leadership practices, technological globalization will bring enormous teaching and learning possibilities for many. Nevertheless, one of the first challenges will be for leaders "to be much less the disseminator and much more the [technologically-savvy] facilitator" (Bottery, 2006 p.12). This will require new types of managerial styles and strategies in addition to emergent paradigms of educational leadership. An additional consideration is the fact that technological improvements generally only improve the lives of those who are able to afford them or who have access to them. As a result, it is absolutely essential that educationalists are not only aware of the dangers posed by such divisions between rich and poor, but that leaders also equip themselves with the ability to handle and assess these types of issues and realize that "when such disparities of wealth are allied to the gap widening effects of neo-liberal forms of economics, as well as the perceived threats to ways of life from forms of cultural globalization, another potential globalization is nurtured - the globalization of terrorism" (Bottery, 2006 p.12).

\section{Emerging Global Trends in Educational Leadership}

There is no doubt that all of the aforementioned dimensions of globalization will have enormous impacts on educational leadership. One of the most obvious effects will be the fact that societies will increasingly expect that 
educational leaders will be able to cope with the increasingly difficult and complex challenges that arise in the $21^{\text {st }}$ century. They will also require leaders to uphold core principles of social transformation (e.g. social justice, equity etc.) as well as demonstrating visionary capacity, boundary-breaking entrepreneurialism, new professional skills, instructional design and assessment literacy, and crisis management (Scott \& Webber, 2008) in this new global era and this will inevitably necessitate the emergence of a variety of new and important trends in educational management practices and leadership paradigms. The following section will briefly analyze some of the more common global leadership theories that have developed in recent years.

\subsection{Transformational Leadership}

While leaders and leadership training programs have had a long-standing affiliation for instructional leadership since the 1970's (Hallinger, 2005b), one paradigm that has recently evolved in response to intensifying global trends and pressures is transformational leadership. Essentially, transformational leadership is rooted in a very 'Westernized' neo-liberal economic and socio-political ethos and it has evolved in conjunction with a growing interest in the relationship between leadership, the culture of an organization, and the notions of change and improvement as being continual and essential processes (Huber \& West, 2002; Huber, 2004). Leithwood (2007) has provided one the most extensive formulations of this type of leadership that includes four major dimensions, each of which are comprised of several more specific sets of practices. They are as follows: setting directions (i.e. building a shared vision, fostering acceptance of group goals, high performance expectations); developing people (i.e. providing individual support and consideration, intellectual stimulation, providing an appropriate model, redesigning the organization); building collaborative cultures (i.e. restructuring, building productive relationships with stakeholders and communities, connecting the school to a wider environment, managing the instructional program); and staffing the program (i.e. providing instructional support, monitoring school activity, buffering staff from distractions to their work).

Although transformational leadership does share some things in common with earlier forms of traditional instructional leadership, Huber (2004) has suggested that the transformational leader is more concerned with the people that are carrying out tasks, on forging relationships and making deliberate efforts to win cooperation and commitment and on actively influencing the culture of the school so that it stimulates more collaboration, coherence, and more independent teaching and learning. Moreover, this style of leadership is somewhat synergistic as it "concentrates on the results, the success of the teaching and learning processes, and on the relation between these outcomes and the specific processes which led to them" (Huber, 2004 p.673). Other proponents of transformational leadership such as Mulford (2008) have suggested that it is a more powerful way of thinking about school leadership than competing approaches (i.e. instructional leadership) "because it leads to an investigation of all workplace conditions that contribute to all school outcomes, not just [pedagogic]...strategies" (p. 41). In addition, it is a visionary form of leading that seeks to generate both first order effects (i.e. valued teacher and student outcomes) as well as generating important second order effects that increase the capacity of others in a school to produce first-order effects on learning (Mulford, 2008). Lastly, Leithwood and Jantzi (2005) have found that transformational leadership can lead to changed classroom practices, collective teacher efficacy, enhanced organizational learning, and an overall improved quality of teaching and learning.

\subsection{Distributed Leadership}

In an effort to enable teacher-leaders, department heads, and even students and stakeholders to take on a more proactive, democratic, and participative role in organizational decision making, a number of theorists have begun to call for an increased focus on developing 'communities of leaders' or distributed leadership (Huber, 2004). This concept of leadership originated in the 1980's and some of its earliest descriptions highlighted the enhanced organizational capacity of institutions that relied upon collective forms of leadership (Sergiovanni, 1984). More recent explanations are much more explicit and focus on specific dimensions of distributed leadership that best contribute to efficiency, efficacy and organizational learning. Bennett, Wise and Woods (2003), for example, suggest that these dimensions include: seeing leadership as an outcome of the dynamics of interpersonal relationships rather than individual action; trust and openness as a basis of interpersonal relationships; letting go by senior administration rather than simply delegating tasks; extending the boundaries of leadership to all communities in the school and not just teachers, thereby creating a team culture throughout the school; not mandating leadership into existence, but growing it; recognizing expertise and not formal positions as the basis of leadership roles within groups; and seeing leadership as fluid rather than located in specific formal roles or positions, thereby blurring the distinction between leaders and followers.

Day and Harris (2002), on the other hand, have provided a more narrowed conceptualization and description of school distributed leadership and argue that there are four discernable and discrete aspects of the teacher leadership 
role. The first feature involves the translation of the principles of school improvement into the practices of every day teaching. It ensures that the links within schools (social capital) are secure and opportunities for growth and development are maximized. The second feature of a teacher leader role focuses on participative leadership in which all teachers are made to feel as though they are a part of change or development and have a sense of ownership. In this way, heads may call upon the staff to join together around a particular development and foster a collaborative way of working. The third feature of teacher leadership is the mediating role in which the teacher leader utilizes the staff's expertise and knowledge in the decision-making process while the final feature involves forging close relationships with individual teachers through which mutual learning takes place.

There is no question that distributed leadership holds great promise and is easily incorporated into models of transformational leadership, but it still has some shortcomings. First, most recent descriptions of this model typically focus on only the inclusion of teachers, but some theorists such as Huber (2004) have suggested that true cooperative and democratic form of distributed leadership need to consist of as many persons from the staff as possible, the students, parents, and other community stakeholders. Mulford (2008), on the other hand, has argued that this form of leadership cannot become all things to all people and the term should not necessarily be used inter-changeably with expressions such as cooperative because cooperative leadership is by definition distributed, but not all forms of distributed leadership can be cooperative. "Similarly,...distributed leadership allows for democratic leadership or autocratic leadership [as well as]...team or non-team leadership" (Mulford, 2008 p.45). An additional problem with distributed leadership stems from the fact that research has shown that it will not occur unless it is genuinely supported and facilitated by a principal. At the same time; however, these same principals can often overestimate their success at having actually achieving distributed leadership (Mulford, 2008). Finally, Mulford (2008) has suggested that successful school leaders do not just put more power and influence in the hands of other people. They should also adopt a focused and explicit approach to their responsibility of developing leadership capacities in all of their staff.

\section{Educational Leadership in Developing Countries}

While the emergence and development of new and effective educational leadership and managerial theories in many 'Western' and/or developed countries has been promising, some authors such as Oplatka (2004) have suggested that some common features of educational leadership in many developing countries include limited autonomy, autocratic and hierarchal leadership styles, low degrees of change initiation, and a lack of distributed or transformational leadership functions. When coupled with a lack of funding and resources, this situation can be viewed as both unfortunate and problematic for many of the world's poor and it implies that many of the K-12 educational systems in developing countries are not particularly efficient or effective. On the other hand, it also brings forth interesting questions and dilemmas regarding international leadership development initiatives and the transferability and applicability of educational leadership paradigms and managerial models that have been predominantly developed in 'Western' nations as there is no question that some form of the sharing of knowledge and ideas will be essential to the formulation of systematic, integrated, and useful leadership development programs and practices in developing countries.

With respect to international educational leadership development schemes, some theorists such as Hallinger and Kantamara (2000) have warned about the ever-increasing range of Western leadership initiatives that are traversing the globe and finding their way into developing countries and traditional cultures. To Hallinger and Kantamara (2000), foreign-directed educational policy reforms and change can sometimes engender more suspicion than enthusiasm at the point of implementation due to the fact that so many countries have had their traditional education systems systematically altered or even destroyed by various forms of colonialism. They have suggested, therefore, that sophisticated and forward-thinking guidance in addition to long-term policy-planning and persistence will be required to bring about genuine leadership reforms, especially where the underlying assumptions are foreign to prevailing norms of the local culture. Karstanje and Webber (2008) have similar views and have pointed out the need for a closer attention to details, a better understanding of local customs and cultural norms and have pointed out that new educational ideas may need long incubation periods in settings where they are introduced. Macpherson, Kachelhoffer, and Medhat (2007) have also called for caution with respect to the transferability and implementation in developing countries of educational policies that originate in 'Western' nations and call for the need to include localized indigenous knowledge in any educational development program; while other theorists such as Brundrett, Slavikova, Karabec, Murden, Dering, and Nicolaido (2006) have made convincing arguments in favour of re-conceptualizing or refocusing principal training programs to reflect local idiosyncrasies and other specific contextual issues. However, at the same time, Oplatka (2004) has argued that there are a number of specific issues that still need to be addressed in regards to the successful execution of educational leadership development plans in developing countries. Such development plans need to provide principals with adequate training on instructional 
issues; provide principals with greater autonomy prior to attempts at implementing educational policies that focus on teaching; address issues of autonomy, democracy, and other 'Western' cultural norms and perceptions in leadership training and teacher in-service programs; change practicing teachers' notions of issues such as reform initiation, school-based management, transformational and distributed leadership; and, most importantly, improve the responsiveness of school leaders and school systems to parents and children. Finally, a number of theorists such as Palmer, Wedgewood, Hayman, King and Thin (2007) have reminded us that any type of international educational development endeavour needs to focus on reducing poverty and other inequalities or little improvement will take place in the educational systems of developing countries.

\section{Recommendations for Future Research}

We have seen that globalization can be interpreted through economic, political, American, socio-cultural, demographic, technological, linguistic, and environmental dimensions. It is important to remember, however, that these dimensions are nothing more than a limited snapshot at one particular point in time and the world of the educational leader is constantly changing. As such, it is absolutely essential for researchers to continue to seek out and examine new and evolving forms of globalization as they develop and unfold. It will also be important for people to study the effects of these new aspects of globalization on educational systems, school leaders, and leader development programs in a variety of different contexts.

Despite the success and attractiveness of new approaches to leading such as transformational leadership and the rising popularity of distributed forms of leadership, the intensifying pressures of globalization will undoubtedly necessitate the evolution of existing theories along with the gradual emergence of a wide array of new and relevant leadership paradigms. Some of these include total quality management (TQM) with its focus on entrepreneurial efficiency and data-literacy (i.e. one's ability to use data to determine areas of success and improve instruction) (Lachat, Williams, \& Smith, 2006; Parker-Boudett, City, \& Murnane, 2006); digital-aged leadership (Mercurius, 2006) with its focus on leaders that are confident, knowledgeable, systematic and strategic, organized, able to communicate and motivate, able to facilitate and cultivate, attuned to the benefits of globalization, and infused with technological-savvy; systems leadership with its focus on leaders who work intensively in their own schools in addition to connecting with and participating in the broader educational system and its wider societal context (Fullan, 2005); and sustainable leadership with its focus on leadership that preserves and develops lasting deep learning for all and that does no harm to others and the world around us (Hargreaves \& Fink, 2006). Additional research needs to be initiated, therefore, on the applicability of these and other similar types of emerging theories to a variety of modern genuine contexts. Moreover, research needs to be conducted on the extent to which existing models of leadership are not only adapting with the times, but also the extent to which these established forms of leadership are merging with and/or diverging from newer models and theories.

A third and final area that is in need of more research concerns the fact that one size does not necessarily fit all when it comes to translating educational leadership theories into practice (Mulford, 2008). As a result, it will be extremely important for educational researchers to not only examine the degree and extent to which predominantly 'Western' leadership theories are transferred to a variety of different countries and cultures around the world (e.g. developing countries), but it will also be crucial to focus additional studies on important developing global trends in principal preparation, leadership development, as well as the actual practice of the principalship. This will enable educationalists to gain a better understanding of the practicality of competing models and the transferability and applicability of 'Western' educational leadership theories to non-'Western' and developing country contexts as well as a deeper appreciation of emerging and alternative models and the increasing complexities of global educational leadership patterns.

\section{Conclusion}

We have seen that globalization has many interconnected, far-reaching, and complex dimensions (economic, political, American, socio-cultural, demographic, linguistic, technological, and environmental); and that these have had an enormous impact on educational systems, leadership paradigms, as well as the broader societies and contexts in which they operate. Some of the positive effects of globalization have included economic growth, technological advancements, political and social integration, the expansion of democracy, the dissemination of knowledge and ideas; and increased learning opportunities while some of the negative outcomes have been rampant consumerism; feelings of disenfranchisement, inequity, animosity and exclusion; environmental degradation; allegations of imperialism and hegemony; and increasing disparities of wealth and other inequalities between developed and developing nations. It is absolutely essential, therefore, that educational leaders and leadership training and development programs are not only able to stay abreast of the important and multi-faceted worldwide trends that 
impact everything they do, but that they are also flexible and able to adapt to the ebb and flow of the constantly-changing forces of globalization in the $21^{\text {st }}$ century.

\section{References}

Beare, H. (2007). Four decades of body-surfing the breakers of school reform: Just waving, not drowning. In T. Townsend (Ed.), International handbook of school effectiveness and improvement (pp.27-40). Dordrecht: Springer. doi:10.1007/978-1-4020-5747-2_2, http://dx.doi.org/10.1007/978-1-4020-5747-2_2

Bennett, N., Wise, C., Woods, P., \& Harvey, J. (2003). Distributed leadership. Nottingham: NCSL.

Berger, P.L. (2007). Many globalizations: The cultural dynamics of globalization. In H. Wiarda (Ed.). Globalization: Universal trends, regional implications. (pp. 23-36). Boston: Northeastern University Press/University Press of New England.

Bottery, M. (2006). Educational leaders in a globalizing world: A new set of priorities? School Leadership and Management, 26(1), 5-22. doi:10.1080/13634230500492822, http://dx.doi.org/10.1080/13634230500492822

Bruff, I. (2005). Making sense of the globalisation debate when engaging in political economy analysis. British Journal of Politics \& International Relations, 7(2), 261-280. doi:10.1111/j.1467-856X.2005.00177.x, http://dx.doi.org/10.1111/j.1467-856X.2005.00177.x

Brundrett, J., Slavikova, L., Karabec, S., Murden, B., Dering, A., \& Nicolaido, M. (2006). Educational leadership development in England and the Czech Republic: Comparing perspectives. School Leadership and Management, 26 (2), 93 - 106. doi:10.1080/13634230600589592, http://dx.doi.org/10.1080/13634230600589592

Bush, T., \& Oduro, G. (2006). New Principals in Africa: Preparation, induction and practice. Journal of Educational Administration, 44(4), 359-375

Crossley, M., \& Tikly, L. (2004). Postcolonial perspectives and comparative and international research in education: a critical introduction. Comparative Education, 40(2), 147-156. doi:10.1080/0305006042000231329, http://dx.doi.org/10.1080/0305006042000231329

Crystal, D. (2003). English as a global language ( $2^{\text {nd }}$ ed.). Cambridge: Cambridge University Press.

Day, C., \& Harris, A. (2002). Teacher leadership, reflective practice and school improvement. In K. Leithwood \& P. Hallinger (Eds.). Second international handbook of educational leadership and administration. (pp. 957-977). Dordrecht: Kluwer Academic Publishers.

Duke, D., Grogan, M., Tucker, P., \& Heinecke, W. (Eds.). (2003). Educational leadership in an age of accountability: The Virginia experience. Albany: State University of New York Press.

Frank, T. (2002). One market under God. Extreme capitalism, market populism, and the end of economic democracy. London: Vintage.

Freedman, L. (2009). A subversive on a hill. The National Interest, (May/June). [Online] Available: http://www.nationalinterest.org/Article.aspx?id=21296 (June 20, 2009)

Fullan, M. (2005). Leadership and sustainability: System thinkers in action. Thousand Oaks: Corwin Press, Toronto Principals Council.

Guo, Y., \& Gulbahar, H.B. (2008). The hegemony of English as a global language. In A. Abdi \& S. Guo (Eds.), Education and social development: Global issues and analyses. (pp. 57-69). Rotterdam: Sense Publishers.

Guttman, C. (2003). Education in and for the Information Society. Paris: UNESCO. [Online] Available: http://portal.unesco.org/ci/en/ev.php-URL_ID=12846\&URL_Do=Do_TOPIC\&URL_SECTION=201.html (June 10, 2009)

Hallinger, P. (2003). Leading educational change: Reflections on the practice of instructional and transformational leadership. Cambridge Journal of Education, 33(3), 329-351. doi:10.1080/0305764032000122005, http://dx.doi.org/10.1080/0305764032000122005

Hallinger, P. (2005). Instructional Leadership: How Has the Model Evolved and What Have we learned? [41p; Paper presented at the American Educational Research Association, April 2005, Montreal]. [Online] Available: http://www.cmmu.net/main/research/document/Leadership\%20Paper\%20Aera\%202005\%201.2[1].pdf (June 20, 2009)

Hallinger, P. (2005). Instructional leadership and the school principal: A passing fancy that refuses to fade away. Leadership and Policy in Schools, 43(3), 1-20. doi:10.1080/15700760500244793, http://dx.doi.org/10.1080/15700760500244793 
Hallinger, P., \& Kantamara, P. (2000). Educational change in Thailand: Opening a window onto leadership as a cultural process. School Leadership and Management, 20(2), 189-205. doi:10.1080/13632430050011425, http://dx.doi.org/10.1080/13632430050011425

Hargreaves, A., \& Fink, D. (2006). Sustainable leadership. San Francisco: Jossey-Bass.

Held, D., McGrew, A., Goldblatt, D., \& Perraton, J. (1999). Global transformations: Politics, economics, culture. Cambridge: Polity.

Held, D., \& McGrew, A. (2007). Introduction: Globalization at risk? In D. Held \& A. McGrew (Eds.). Globalization theory: Approaches and controversies. Malden, MA: Polity press.

Hepp, P.K., Hinostroza, E.S., Laval, E.M., \& Rehbein, L.F. (2004). Technology in schools: Education, ICT \& the knowledge society. [Online] Available: http://www.eldis.org/vfile/upload/1/document/0708/DOC16923.pdf (June 10, 2009)

Huber, S., \& West, M. (2002). Developing school leaders: A critical review of current practices, approaches and issues, and some directions for the future. In K. Leithwood \& P. Hallinger (Eds.), Second international handbook on educational leadership and administration. (pp. 1071-1101). Dordrecht: Kluwer Academic Publishers.

Huber, S. (2004). School leadership and leadership development: Adjusting leadership theories and development programs to values and core purposes of school. Journal of Educational Administration, 42(6), 669-684

Karstanje, P., \& Webber, C. (2008). Programs for school principal preparation in East Europe. Journal of Educational Administration, 46(6), 739 -751

Kennedy, P. (1987). The rise and fall of the great powers: Economic change and military conflict from 1500 to 2000. New York: Random House.

Klein, N. (2000). No logo. London: Flamingo.

Lachat, M., Williams, M., \& Smith, S. (2006). Making sense of all your data. Principal Leadership (High School Ed.). 7(2), 16-21

Leithwood, K. (2007). What we know about educational leadership. In J. Burger, C. Webber, \& P. Klinck (Eds.), Intelligent leadership: Constructs for thinking educational leaders (pp. 41-66). Dordrecht: Springer. doi:10.1007/978-1-4020-6022-9_4, http://dx.doi.org/10.1007/978-1-4020-6022-9_4

Leithwood, K., \& Jantzi, D. (2005). A review of transformational school leadership research: 1996-2005. Leadership and Policy in Schools, 6(1), 177-199. doi:10.1080/15700760500244769, http://dx.doi.org/10.1080/15700760500244769

Macpherson, R., Kachelhoffer, P., \& Medhat, E.M. (2007). The radical modernization of school and education system leadership in the United Arab Emirates: Towards indigenized and educative leadership. International Studies in Educational Administration, 35(1), 60-77

Mercurius, N. (2006). Leadership: Become a digital-age thinker. Tech and Learning. [Online] Available: http://www.techlearning,com/story/showArticle.jhtml?articleID=180204173 (June 15, 2009)

Mortimore, P. (2001). Globalisation, effectiveness and improvement. School Effectiveness and Improvement, 12(1), 229-249. doi:10.1076/sesi.12.2.229.3453, http://dx.doi.org/10.1076/sesi.12.2.229.3453

Mulford, W. (2008). The leadership challenge: Improving learning in schools. Melbourne: Australian Council for Educational Research. Australian Education Review.

Oplatka, I. (2004). The principalship in developing countries: context, characteristics and reality. Comparative Education, 40(3), 427-448. doi:10.1080/0305006042000274872, http://dx.doi.org/10.1080/0305006042000274872

Palmer, R., Wedgewood, R., Hayman, R., King, K., \& Thin, N. (2007). Educating out of poverty: A synthesis report on Ghana, India, Kenya, Rwanda, Tanzania and South Africa. London: Department for International Development.

Parker-Boudett, K., City, E., \& Murnane, R. (2006). The 'data wise' improvement process: Eight steps for using test data to improve teaching and learning. Principal Leadership (Middle School Ed.). 7(2), 53-56

Phillipson, R. (1992), Linguistic imperialism. Oxford University Press.

Porter, J. (1999). Reschooling and the global future: Politics, economics, and the English experience. Oxford: Symposium Books. 
Rego, P.M. (2007). The United States: Is America the universal nation? In H. Wiarda (Ed.). Globalization: Universal trends, regional implications. (pp. 83-104). Boston: Northeastern University Press/University Press of New England.

Robertson, S., Novelli, M., Dale, R., Tikly, L., Dachi, H., \& Alphonce, N. (2007). Globalisation, education and development: Ideas, actors and dynamics. London: Department for International Development.

Scott, S., \& Webber, C.F. (2008). Evidence-based leadership development: The 4L framework. Journal of Educational Administration, 46(6), 762-776. doi:10.1108/09578230810908343, http://dx.doi.org/10.1108/09578230810908343

Sergiovanni, T. (1984). Leadership and excellence in schooling. Excellent schools need freedom within boundaries. Educational Leadership, 41(5), 4-14

Shizha, M. (2008). Globalization and indigenous knowledge: An African post-colonial theoretical analysis. In A. Abdi \& S. Guo (Eds.), Education and social development: Global issues and analyses. (pp. 37-56). Rotterdam: Sense Publishers.

Smith, M.K. (2002). Globalization and the incorporation of education. The encyclopaedia of informal education. [Online] Available: http://www.infed.org/biblio/globalization.html (June 10, 2009)

Smith, M.K., \& Smith, M. (2002). Globalization. The encyclopaedia of informal education. [Online] Available: http://www.infed.org/biblio/globalization.html (June 10, 2009)

Social Science Research Council (n.d.). (2009). Teaching guide for 'globalization' essays. [Online] Available: http://essays.ssrc.org/sept11/essays/tr_globalization.html (June 15, 2009)

Tikly, L. (2001). Globalisation and education in the postcolonial world: Towards a conceptual framework. Comparative Education, 37(2), 151-171. doi:10.1080/03050060124481, http://dx.doi.org/10.1080/03050060124481

Wiarda, H.J. (2007). Has the "end of history" arrived? Globalization's proponents and opponents. In H. Wiarda (Ed.). Globalization: Universal trends, regional implications. (pp. 54-79). Boston: Northeastern University Press/University Press of New England. 